\title{
Notas preliminares sobre o cantochão acompanhado na prática musical luso- brasileira dos séculos XVIIl e XIX: o Hino a São João Batista de José Maurício Nunes Garcia
}

\author{
André Guerra Cotta (Acervo Curt Lange-UFMG) \\ andregc@uol.com.br
}

\begin{abstract}
Resumo: A partir de registros que comprovam o uso de acompanhamento do cantochão na prática musical de catedrais brasileiras nos séculos XVIII e XIX, este estudo procura discutir preliminarmente a utilização de documentos pertencentes ao Cabido Metropolitano do Rio de Janeiro (RJ) para a realização deste tipo de repertório, exemplificado no Hino a São João Batista de José Maurício Nunes Garcia. Busca estimular futuros estudos sobre o tema e, sobretudo, a performance desta música. Indiretamente, pretende-se fornecer subsídios para novas formas de utilização do instrumento catedralício por excelência - o órgão de tubos - re-inserindo este repertório litúrgico nas práticas sócio-culturais e musicais atualmente em voga, estimulando a reutilização deste instrumento nos circuitos históricos brasileiros em que se encontram. Palavras-chave: Cantochão, órgão, música sacra, práticas de performance, José Maurício Nunes Garcia, musicologia histórica brasileira
\end{abstract}

Preliminary notes on the accompanied plainchaint in the nineteenth- and twentieth-century BrazilianPortuguese musical practice: the Hymn to St. John the Baptist by José Maurício Nunes Garcia

\begin{abstract}
Departing from evidences of the use of accompanied plainchant in the musical practice of Brazilian cathedrals in the nineteenth and twentieth centuries, this study discusses preliminarily the use of documents belonging to the Cabido Metropolitano do Rio de Janeiro (Brazil) to support the realization of this type of repertoire, exemplified in Hymn to St. John the Baptist by Brazilian composer José Maurício Nunes Garcia. It also encourages future studies on this subject and, especially, the performance of this music. Indirectly, it intends to give subsidies for new forms of use of the organ, re-inserting this liturgical repertoire in the present cultural and musical practices, stimulating the use of this instrument in the Brazilian historical circuits in which some exemplars remain.
\end{abstract}

Keywords: Plainchant, organ, sacred music, performance practice, José Maurício Nunes Garcia, Brazilian historical musicology

\section{1- Introdução}

Esta breve comunicação pretende apresentar alguns indícios que atestam a prática de acompanhar 0 cantochão em catedrais na cultura católica lusobrasileira dos séculos XVIII e XIX. Estabelecidas algumas fontes e comprovada tal prática, pretende-se apresentar edição prática de uma obra de José Maurício Nunes Garcia, Mestre de Capela na Sé Catedral do Rio de Janeiro, para exemplificar tal possibilidade no presente. 0 presente trabalho se baseia em pesquisa documental de fontes primárias e em literatura auxiliar, a partir da qual realizou-se um trabalho de interpretação de fontes primárias selecionadas para estudo. A partir do exame da documentação encontrada no Acervo do Cabido Metropolitano do Rio de Janeiro, realizou-se uma revisão bibliográfica sobre o acompanhamento de cantochão e uma pesquisa documental nos catálogos de acervos mineiros, complementando com a edição de algumas das obras selecionadas para estudo. Os procedimentos editoriais basearam-se em FIGUEIREDO (2000) e GRIER (1996). A partir da realização do baixo contínuo e da sua aplicação experimental ao repertório selecionado, passou-se à elaboração do presente artigo, que traz os resultados mais significativos, embora não pretenda, de forma alguma, exaurir o tema.

\section{2- As fontes}

0 presente trabalho começou a ser vislumbrado a partir dos resultados do projeto Digitalização do Acervo do Cabido Metropolitano do Rio de Janeiro, através do qual, depois de décadas de impedimento do acesso por parte da comunidade de pesquisa musical, este acervo tornou-se disponível através de um sítio web. ${ }^{1}$ Através de fac-símiles digitais, foi possível acessar os documentos pertencentes àquele acervo, fontes de grande importância para a história da música no Brasil, pelo seu caráter único e pelo seu inestimável valor informacional. Entre tais fontes 
encontram-se autógrafos de José Maurício Nunes Garcia e outros músicos atuantes na Capela Real (depois nomeada Capela Imperial), contendo obras de grande envergadura, tais como Ofícios, Missas e Hinos de Ação de Graças (Te Deum), registradas em partes ou mesmo em partituras.

Porém, chamam a atenção várias peças curtas de José Maurício, registradas em partes autógrafas para coro a quatro vozes e órgão, para diversas ocasiões do ofício litúrgico católico, nas quais encontram-se claras indicações de algo que normalmente fica nas entrelinhas: o acompanhamento, com o órgão de tubos, de trechos de cantochão, precisamente indicados nas partes deste instrumento presentes em tais peças curtas para coro a quatro vozes. ${ }^{2}$ Trata-se, muito provavelmente, de orientações para que ele próprio realizasse 0 acompanhamento ao órgão, na Capela Real, onde atuou como Mestre de Capela e organista.

Estas evidências somam-se a indícios presentes em algumas obras de história da música no Brasil em que se menciona a prática do cantochão e a grande quantidade de órgãos existentes no Brasil, porém sem nenhuma indicação concreta de como se realizava o cantochão e sem evidências precisas em documentação musical (cf., por exemplo, CERNICCHIARO, 1926; SANTOS, 1942). Na historiografia musical européia, por outro lado, há registros de grande variedade de formas de acompanhamento do cantochão, inclusive pelo serpentão e pelo oficleide, práticas que foram aos poucos cedendo lugar ao uso do órgão (HILLMAN, 1980), e até mesmo práticas de acompanhamento vocal do Cantochão (SHORE, 1934-1935).

Tais evidências se contrapõem à completa ausência de partes de órgão no acervo do Museu da Música de Mariana, cidade em cuja Catedral encontra-se um dos mais preciosos exemplares de órgão de tubos existentes no pais, um Arp Schnitger, doado pelo Rei de Portugal àquela Sé em meados do século XVIII. ${ }^{3}$ Contrariando todas as expectativas, não se encontra no acervo do Museu da Música de Mariana praticamente nenhuma peça para órgão (com raras exceções de fins do século XIX e princípios do XX, mas não relacionadas ao cantochão). Tampouco se encontrou algum documento que indicasse precisamente 0 uso do órgão na música litúrgica para aquela Catedral em fins do século XVIII e princípios do XIX. Tal fato leva a se pensar, primeiramente, na possibilidade de perda de fontes documentais que se relacionassem com o uso do órgão na Catedral de Mariana. Contudo, diante das evidências encontradas nos documentos da Sé Catedral do Rio de Janeiro, pode-se pensar também na existência de uma tradição de acompanhamento do cantochão pelo órgão de tubos, que, embora nem sempre fosse grafada, encontra alguns registros tais como os hinos de José Maurício.

É igualmente inquietante a desaparição de muitos órgãos de tubos existentes nas igrejas brasileiras dos séculos XVIII e XIX - um exemplo é o completo desaparecimento dos vários órgãos construídos em Minas Gerais pelo organeiro Athanasio Fernandes da Silva, que residiu em Itabira e atuou em toda a capitania e também na própria Catedral do Rio de Janeiro, neste caso reparando o órgão, em $1833 .{ }^{4}$ Também em Itabira, tal qual ocorreu em Mariana, não só não existe nenhum resquício do órgão ouvido por SaintHilaire em 1817, como é intrigante a total ausência de partes manuscritas para órgão no acervo mais antigo da cidade, o da Banda Euterpe Itabirana (que, embora seja o arquivo de uma banda, contém muita música sacra a capella ou acompanhada por orquestra). Estes casos refletem uma problemática presente em outras cidades e regiões do país. A existência das fontes autógrafas de José Mauricio no Acervo do Cabido Metropolitano do Rio de Janeiro vem modificar esse cenário de ausências e lacunas.

\section{3- Um exemplo de cantochão acompanhado: o Hino a São João Batista de José Maurício Nunes Garcia}

José Maurício indica, nas partes de órgão das obras mencionadas (cf. nota 2), um trecho indicado pela palavra "Coro", que corresponde justamente ao cantochão, alternado com um trecho intitulado "Muzica", que é precisamente escrita homofônica a quatro vozes, como mostra a Fig. 1.

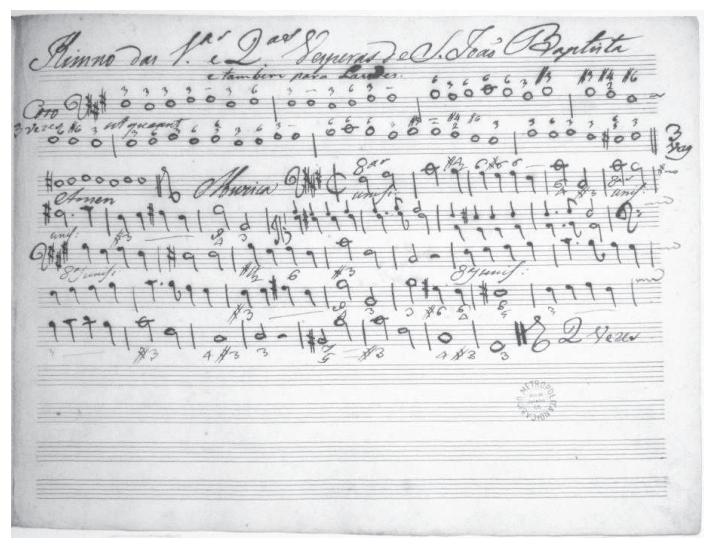

Fig.1: parte de órgão com as indicações de "Coro" e "Muzica" (ACMRJ-CRI-SM33) 
Este padrão se repete em todas as fontes de hinos existentes no Cabido, como mencionado acima. Como se pode ver na parte de órgão acima, do Hino a São João Batista, José Maurício também indica, através de cifragem, a harmonia com a qual se deve acompanhar o trecho em cantochão ao órgão.

A particularidade destes documentos é a de explicitar uma prática que certamente foi fundada na tradição litúrgica lusitana e que parece ser comentada em alguns tratados de cantochão portugueses. Não pretendemos neste breve estudo estender a pesquisa no que diz respeito a tais tratados (até mesmo pela dificuldade de acesso a certas fontes), mas sim propor uma aplicação prática da peça acima mencionada, facilitando com que seja efetivamente levada em performance, por exemplo, em recitais como os que se fazem na Catedral de Mariana, ou, futuramente, na antiga Sé do Rio de Janeiro, onde o órgão em que tocou José Maurício está em vias de ser restaurado, ou ainda nos órgãos da Matriz de Santo Antonio, de Tiradentes
(MG) e da Igreja do Carmo de Diamantina (MG), neste último caso, tratando-se do instrumento em que tocou José Joaquim Emerico Lobo de Mesquita.

Escolhemos como exemplo o Hino para as Primeiras e Segundas Vésperas de São João Batista, cuja parte de órgão foi mostrada na Fig.1. A simples edição em software mostra como um tal uso do cantochão pode ser bastante expressivo e traz interesse não somente histórico, mas também musical. Sem propor aqui maior aprofundamento teórico, gostariamos apenas de apresentar uma edição prática deste hino (cf. ANEXO). Ele se mostra interessante para realização em concerto não somente pelo já exposto, mas também por que se trata do texto utilizado por Guido D'Arezzo para criar, utilizando a primeira estrofe do hino, o seu sistema de nomenclatura das notas musicais (o que pode ser um dos aspectos a ressaltar para o público em um concerto, mostrando um dos importantes vínculos entre este repertório e a própria teoria musical ocidental). A primeira estrofe, tão conhecida, é a seguinte:

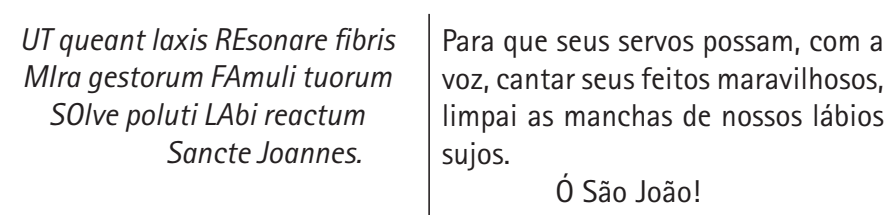

0 hino completo, porém, tem cinco estrofes, como se pode verificar no próprio Liber Usualis, sendo as demais:

Nuntius celso veniens Olympo, te patri magnum fore nasciturum, nomen et vitae seriem gerendae ordine promit.

Ille promissi dubius superni perdidit promptae modulos loquelae: sed reformasti genitus peremptae organa vocis.

Ventris obstruso recubans cubili senseras Regem thalamo manentem hinc parens nati meritis uterque abdita pandit.

Sit decus Patri, genitaeque proli, et tibi compar utriusque virtus, Spiritus semper, Deus unus, omni temporis aevo. Amen.
Um anjo veio dos céus para anunciar a seu pai a grandeza de seu nascimento, ditando o nome que você deveria levar e descobrindo o curso de seu destino.

Ele (Zacarias) duvidou destas promessas divinas e foi privado do uso da fala; mas quando você nasceu recuperou a voz que tinha perdido.

Ainda preso ao peito de sua mãe, você sentia a presença do Rei na morada no útero de vestal. E profeta, antes de nascer, você revelou este mistério a seus pais.

Glória ao Pai e ao Filho gerado; glória semelhante ao Espírito Santo que é nó de ambos, por todos os séculos. Amém. ${ }^{5}$
Do ponto de vista melódico, este hino tem duas versões. Diferentemente da versão de cantochão utilizada por José
Mauricio (cf. Fig.1 acima), o Liber Usualis registra outra versão, que é aquela utilizada por Guido d'Arezzo (Fig.2): 
Capitulum.

Isaiae 49.

I Udite insulae, et atténdite pópu- | vocávit me, * de ventre matris meae Al de longe : † Dóminus ab útero recordátus est nóminis mei.
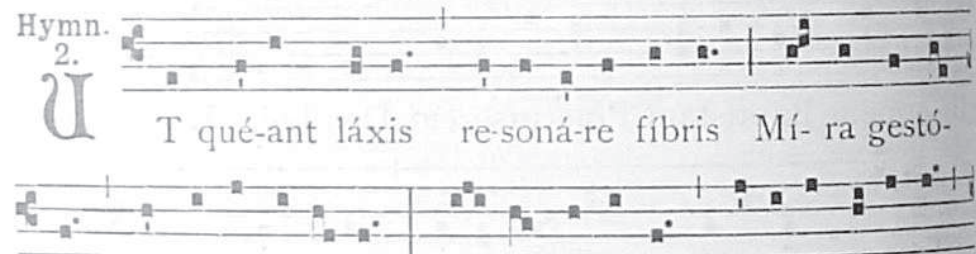

rum fámu-li tu-ó-rum, Sól-ve pollú-ti lábi-i re-á-tum,

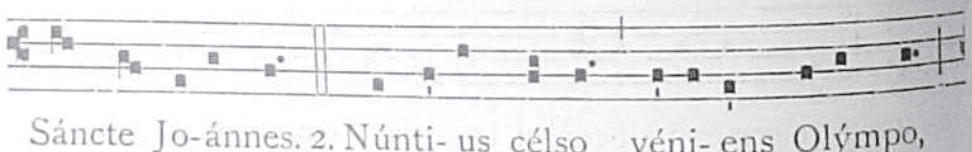

Sáncte Jo-ánnes. 2. Núnti-us célso véni-ens Olýmpo,

Fig.2: Trecho inicial do hino Ut queant laxis no Liber Usualis (p.1504).
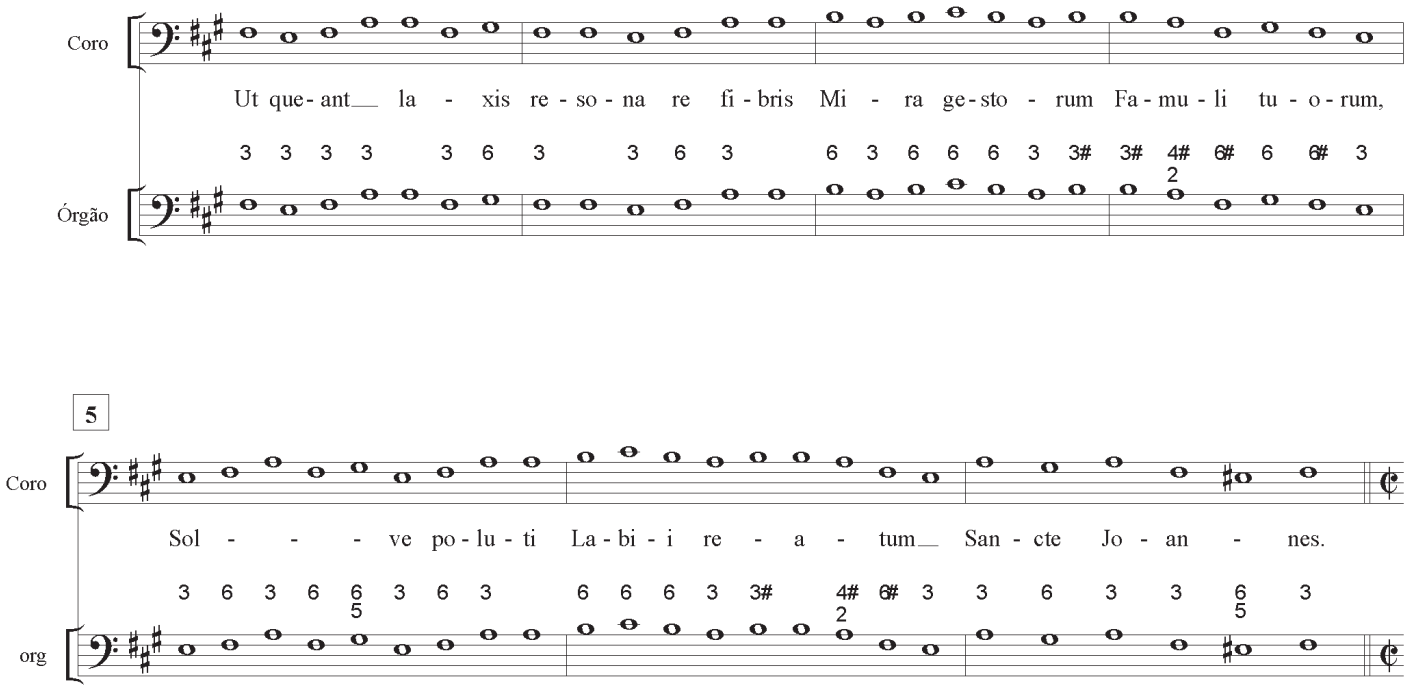

Fig.3: Trecho inicial do hino Ut queant laxis em edição moderna.

Já a versão utilizada por José Maurício está apresentada na Fig.3, em edição moderna, mantendo o baixo cifrado tal como por ele proposto (neste caso contendo somente o texto da primeira estrofe):

Contudo, seguindo a estrutura de cinco estrofes, é possivel encaixar as três estrofes impares indicadas apenas pela instrução "3 vezes" deixada no manuscrito (cf. Fig.1 acima), alternando-se com a parte de escrita homofônica, na qual se cantam a quatro vozes as estrofes pares, 0 que é indicado pela instrução "2 vezes" (cf. Fig.1 acima). Uma edição moderna deste hino deve, portanto, indicar claramente as diversas estrofes, sendo alternadas entre cantochão e coro a quatro vozes homofônicas, tendo, em ambos os casos, acompanhamento do órgão.
É claro que, em se tratando de instrumento tão rico e complexo, são muitas as possibilidades de realização do baixo cifrado de José Maurício, não somente por que a sonoridade muda muito em função da registração e de elementos harmônicos possíveis (sem mencionar, claro, aspectos agógicos e articulatórios), mas, sobretudo, pelas próprias características deste instrumento, cada exemplar sendo único e particular. Corremos aqui, portanto, o risco de adentrar o terreno de especialistas neste instrumento, mas ao propor a presente abordagem nossa intenção é apenas a de estimular a pesquisa e a performance desta música, especialmente deste elemento particular que é o cantochão acompanhado. Não se pretende aqui, evidentemente, oferecer nenhuma versão "definitiva", mas sim possibilidades 
de explorar as instruções deixadas por José Maurício, sem entrar em especificidades do instrumento, que devem ser tratadas, claro, por especialistas neste. Feitas tais considerações, uma possivel realização deste acompanhamento cifrado (Fig.4) seria apenas montar, sobre o baixo, os acordes indicados (tomando-se o "3" como indicação para a tríade):
É possível, entretanto, abrandar os paralelismos de quinta empregando somente a terça em algumas passagens, sobretudo naquelas compostas exclusivamente por este tipo de acorde, como na Fig.5. Porém, existem muitas formas de criar um acompanhamento para o cantochão e há uma literatura relativamente vasta sobre o tema, de modo que o que mostramos aqui é apenas uma estrutura harmônica básica, sobre a qual este pode se estabelecer.
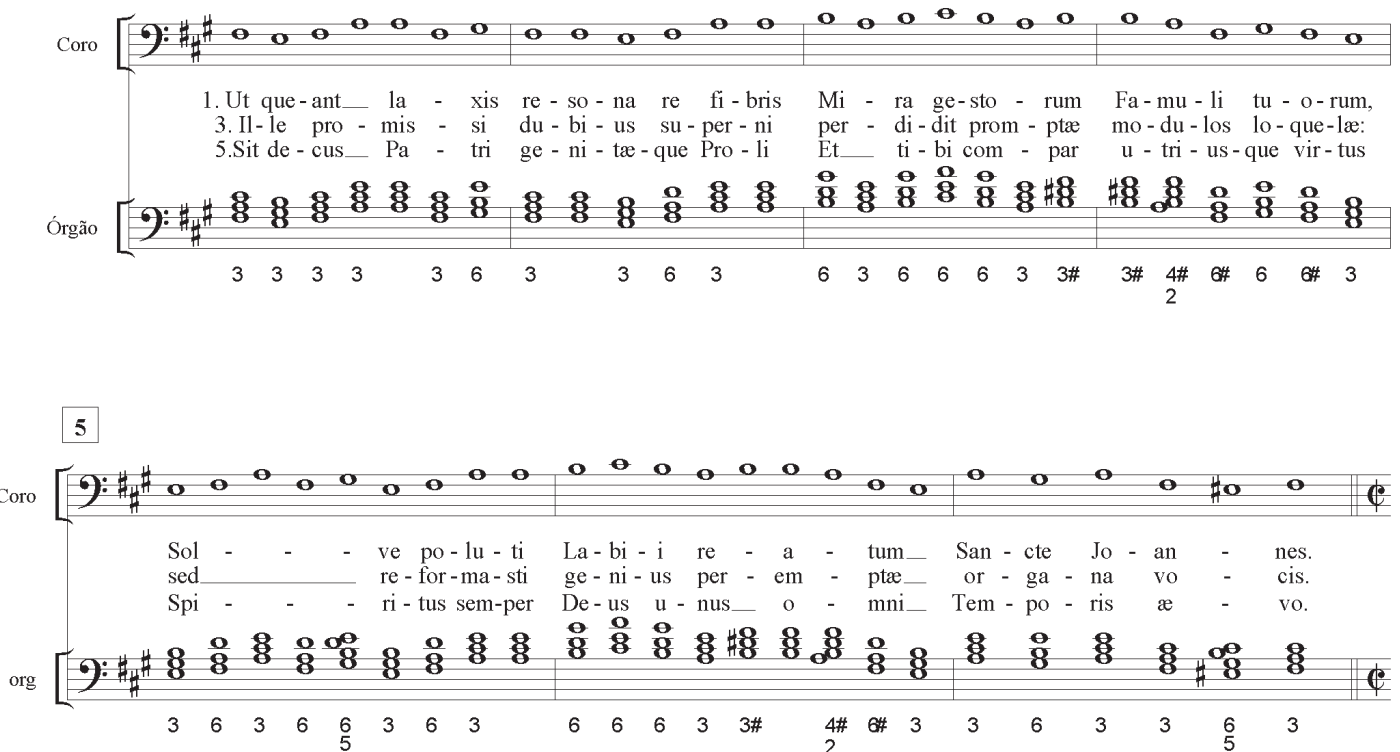

Fig.4: Cantochão do hino Ut queant laxis em edição moderna com possivel realização do baixo cifrado
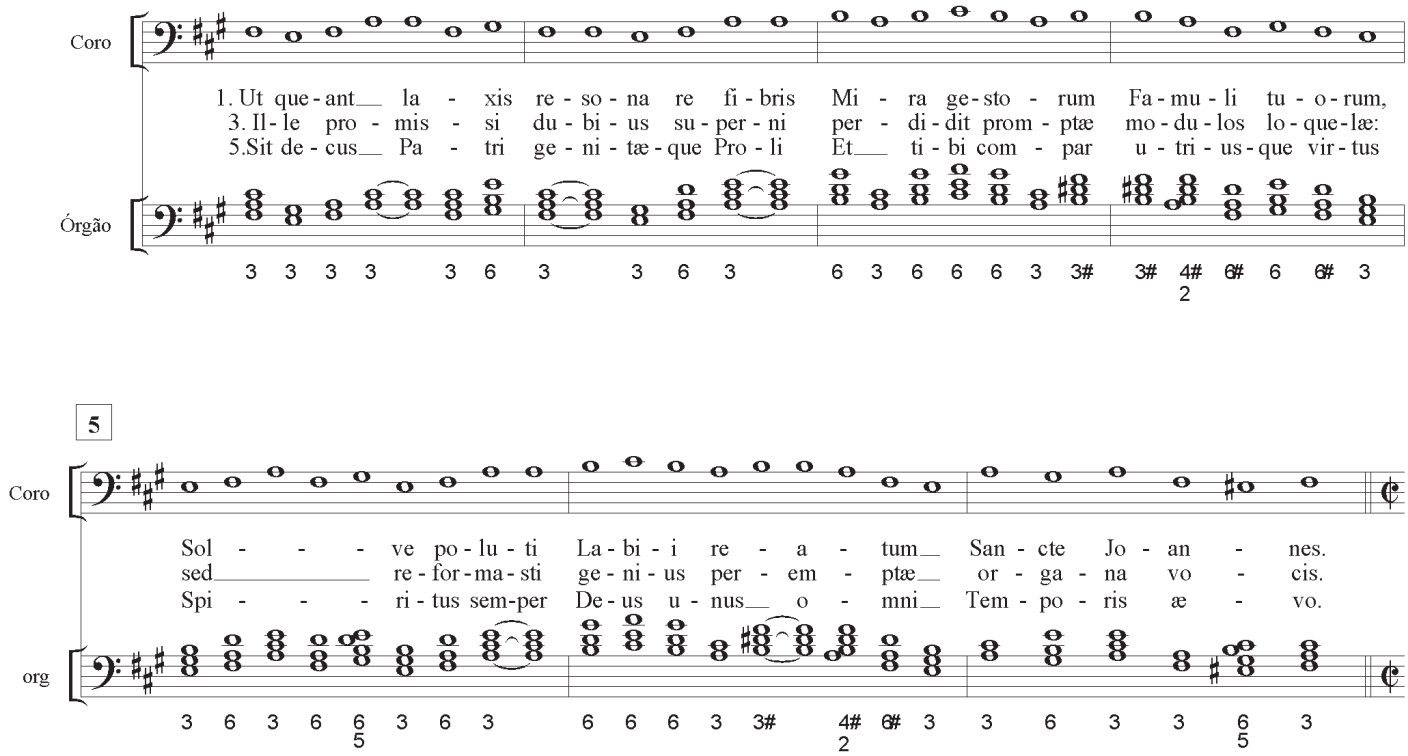

Fig.5: Cantochão do hino Ut queant laxis em edição moderna com realização do baixo cifrado levemente variada 


\section{4- Considerações finais}

0 estudo das 26 obras de José Maurício Nunes Garcia acima mencionadas, que contém indicações para 0 acompanhamento do cantochão em hinos e cânticos do ofício católico, pode contribuir para o estabelecimento de princípios que ajudarão a re-introduzir tal prática de forma historicamente informada, sobretudo para sua aplicação em órgãos históricos. Estabelecidos tais princípios, a possibilidade de aplicá-los, em caráter experimental, a obras de características similares existentes em outros acervos como o Museu da Música de Mariana (MG) e a Coleção Francisco Curt Lange, do Museu da Inconfidência de Ouro Preto (MG), mostrar-se-ia extremamente enriquecedora.

Pretende-se, assim, estimular futuros estudos sobre o tema e, sobretudo, a performance do cantochão acompanhado. Indiretamente, podem-se fornecer subsídios para novas formas de utilização do instrumento eclesiástico por excelência - o órgão de tubos - re-inserindo repertório litúrgico católico nas práticas sócio-culturais e musicais atualmente correntes, seja nas antigas capitais do país, como Rio de Janeiro e Salvador, seja no circuito de cidades históricas de Minas Gerais, mas também em outros sítios em que tais práticas possam ter existido. Isto viria a enriquecer o repertório praticado em concertos de órgão, que geralmente trazem apenas obras instrumentais profanas, geralmente ligadas ao barroco alemão.

0 estudo da prática lusitana (ou mesmo em outras culturas musicais européias) de acompanhamento do cantochão, em relação à qual o uso do fabordão é freqüentemente mencionado, é também uma rica possibilidade de contribuir para o conhecimento desta prática na América Portuguesa. Além disso, cabe ressaltar que muitas vezes o trecho do "coro" é simplesmente subentendido nas partes, o que exige do editor o trabalho de reconstruir as estruturas das estrofes e, assim, a alternância entre cantochão e canto de órgão, sendo que os dois, o cantochão inclusive, podem ser acompanhados, ainda que não esteja o acompanhamento registrado explicitamente como no caso aqui estudado. 


\section{Referências}

CERNICCHIARO, Vincenzo. A Storia della música nel Brasile. Dai tempi coloniali sino ai nostri giorni (1549-1925). Milano: Fratelli Riccioni, 1926.

FIGUEIRED0, Carlos Alberto. Editar José Maurício Nunes Garcia. Tese de Doutorado submetida ao Programa de Pósgraduação em Música do Centro de Letras e Artes da Universidade do Rio de Janeiro (UNI-RIO). Rio de Janeiro, 2000.

GRIER, James. The Critical Editing of Music: History, Method, and Practice. Cambridge: Cambridge University Press, 1996.

HILLSMAN, Walter. Instrumental Accompaniment of Plain-Chant in France from the Late 18th. Century. The Galpin Society Journal, Vol. 33, mar, 1980, pp. 8-16.

Liber Usualis. Missae et Officii. Tournai: Desclée, 1962.

SANTOS, Maria Luiza de Queiroz Amâncio dos. Origem e evolução da música em Portugal e sua influencia no Brasil. Rio de Janeiro: Imprensa Nacional, 1942.

SHORE, S. Royle. The Vocal Accompaniment of Plainchant. Proceedings of the Musical Association, 61st Sess, 1934-1935, p. 105-125.

André Guerra Cotta é Musicólogo, Bacharel em Regência e Especialista em Musicologia Histórica Brasileira pela Escola de Música da Universidade Federal de Minas Gerais. Mestre em Ciência da Informação pela Escola de Ciência da Informação da mesma universidade, com a dissertação 0 tratamento da informação em acervos de manuscritos musicais brasileiros, na qual propôs as bases de uma arquivologia musical. Coordenador do Projeto Conservação e Instalação Definitiva do Acervo Curt Lange (UFMG/FUNDEP/PETROBRAS, 2005-2006). Atualmente coordena o Acervo Curt Lange-UFMG, é responsável pela instalação do acervo e treinamento de equipe no Projeto Instalação e Difusão do Museu da Música de Mariana (PETROBRAS/FUNDARO) e é Doutorando em Musicologia pela UNIRIO.

\section{Notas}

10 resultado deste projeto pode ser encontrado em http://www.acmerj.com.br, inclusive as fontes aqui mencionadas.

2 Trata-se de 26 pequenas peças (25 hinos e um cântico) existentes nos documentos ACMRJ-CRI-SM025, ACMRJ-CRI-SM026, ACMRJ-CRI-SM027, ACMRJ-CRI-SM028, ACMRJ-CRI-SM029, ACMRJ-CRI-SM030, ACMRJ-CRI-SM033, ACMRJ-CRI-SM034, ACMRJ-CRI-SM035, ACMRJ-CRI-SM036 e ACMRJ-CRI-SM037. Cf. www.acmerj.com.br.

3 Sobre o Órgão da Sé, cf. http://www.orgaodase.com.br/inicio_pg/inicio_frame.htm.

4 Tal como consta no Livro de Receita e Despesa da Catedral e Capela Real e Imperial (1823-1843), folio 19r. Documento armazenado na caixa 103.

5 Propomos aqui uma tradução realizada a partir do cotejamento entre o texto latino e uma tradução para o inglês (cf. http://interletras.com/ canticum/Eng/translation_various.html). 